no longer great, and does not by any means account for the difference in results between the two countries. The German student as a rule works very much longer, that is, he is a student for a longer time than the English student, who too often commences his study of chemistry not as a mental training but as a means to an end: to become a public analyst or a works analyst, and who dejires to learn only as much as is absolutely necessary for some particular line he has chalked out for himself; or, worse still, to "pass" some "examination."

The importance of chemistry, especially that more regular and systematic chemistry of the carbon compounds; as a philosophical training is not yet by any means recognised in this country. And it is to be feared that until this is remedied we shall still remain, in spite of new schools, in a backward position.

According to an authority like Prof. Wundt, even qualitative and quantitative analysis are, as logical methods, superior to mathematical. ${ }^{1}$

There is no reason to suppose that the ordinary English student is inferior to any other, and when this subject is put before him in a proper light, as a mental training of the highest order, and not simply a mechanical sort of process, more cheerful results may be looked for. But the students in our higher schools and universities should not stop at qualitative and quantitative analysis, but if possible do some synthetic work, as by this only is a real grasp of the science to be obtained.

When once we get a substratum of well-trained students, not simply analytical machines, or examinationpassers, we shall not have long to wait for results of theoretical and also practical interest.

But our professors must also bestir themselves. In very few institutions in England are more than elementary courses of lectures given, generally the same thing one session after another. The professor should always be practically engaged in research work, so that his students may have a real example to follow. This of course can only take place when the present disproportionate amount of teaching is reduced. Certain it appears that the enthusiasm and rapid advance of the students working in a German university laboratory is in a great measure, probably entirely, due to the example of the professor's working.

\section{THE CHOLERA BACILLUS}

THE Report in which Dr. Koch, chief of the German Scientific Expedition, embodies the results hitherto obtained by him and his assistants with regard to the cholera in Egypt, deals in a very guarded manner with the question of the discovery of a definite cholera bacillus. As the result of experiments carried out both on living and dead cholera subjects, it appears that, whereas no distinct organism could be traced in the blood and in the organs which are so frequently the seat of micro-parasites, yet bacteria having distinct characteristics and resembling somewhat in size and form the bacilli found in glanders were discovered in the intestines and their mucous linings; and this under circumstances which seemed to identify them with the disease from which the patients were suffering. Thus, their existence in the intestinal membranes was obvious so soon after death that they could not have been brought about by any post-mortem changes; they were present in the case of all patients who were actually suffering from the disease, and in the bodies of all those who had died of it, whereas they were abjent in the case of one patient who had had time to recover from cholera but who had died of some secondary complication; and they were not discoverable in the case of patients who, during the cholera epidemic, succumbed to other diseases. And further, the same bacillus had been met with by Dr. Koch, a year previously, in the case of four patients who had died of cholera in India, and portions of whose intestines had been forwarded to him for examination.

From these circumstances Dr. Koch feels justified in provisionally holding the belief that these bacilli are in some way related to cholera, but as yet he is not prepared to say whether they are the cause or the effect of that disease. The number of cases which the Scientific Expedition were able to utilise for the purposes of their inquiry was very limited, and it is also suggested as possible that some of the experiments were vitiated owing to the circumstance that the disease was already subsiding in intensity when the investigations were commenced. Especially does Dr. Koch suggest that this may account for the invariable failure to produce cholera in any of the lower animals into whose bodies the intestinal secretions were inoculated; but as to this it must be remembered that human diseases are rarely communicable to other animals, and that, as regards enteric fever, a disease which etiologically and otherwise has many points of resemblance with cholera, every effort to communicate it to other mammalia has hitherto invariably failed. But the failure of infective power which may very possibly be associated with the declining stage of an epidemic would be very likely to interfere with experiments having for their object the isolation and cultivation of the bacillus, and hence we are glad to learn that Dr. Koch is to continue his investigations in India, where the varying stages of the disease can easily be met with. In the meantime, however, it will be well to remember that Drs. Lewis and Cuningham have, notwithstanding laborious microscopic and other researches in India, hitherto failed to identify any of the organisms they have met with as specifically related to cholera.

One point is set at rest by Dr. Koch's Report, and that relates to the actual nature of the disease which has been epidemic in Egypt. Both pathologically and otherwise he declares it to be identical with Asiatic cholera.

\section{NATIONAL TRAITS IN SCIENCE}

THERE are at present three principal currents of scientific work-German, English, and French. The scientific writings of each nationality are characteristic, and, taken as a whole, offer in each case distinctive qualities. German influence is now predominant over the scientific world, as French influence was uppermost during the earlier part of this century; but the sway of Germany over Western thought is far more potent and widespread than was ever that of France. As students once gathered in Paris, so they now flock to Germany and thence back to their own lands they carry the notions of German science, and labour to extend, imitate, and rival them. Thus German ideas have been spread abroad, and established in foreign countries. This has set a common standard for scientific work, which is accepted in most European countries. German influence is evident by its effects in Switzerland, Russia, Italy, Poland, Belgium, England, and America, and in degrees indicated by the order given: in France, Spain, and Portugal it is hardly noticeable. Holland and the Scandinavian countries have for many years achieved so much and so excellent work that their scientific development may be said to have accompanied rather than to have followed that of Germany.

German science has unquestionably distinctive qualities. Its pursuit is a special and honoured calling, attractive to the highest talent: its productions have the stamp of professional work. The German scientific man is first and principally an investigator: he is obliged to be so, otherwise he loses in the race. He wins his posi- 
tion in the hierarchy of learning by the original researches he carries out. To succeed under these circumstances, a man must discover something which is a real addition to knowledge; and to do this, he must be thoroughly familiar with all that has been previously accomplished in his field. Moreover, to advance beyond his peers, the investigator must utilise every possible extraneous advantage; more especially must he have a mastery over the methods to be employed, and be familiar with all rovelties and refinements therein. It cannot be gainsaid that these requirements are more fully answered in Germany than anywhere else. It is certain that, excepting of course a small minority, German scientific publications always contain something really new, and unknown before: each article is a scientific progress, which, however slight, still brings an actual increment to our store of information. Another result of this professional thoroughness is equally striking and characteristic. Being fully posted as to the status of his department, the German of ten displays a singularly just and keen appreciation of what problems are for the moment best worth studying, as being open for solution, and leading to something farther, or else filling a gap left. He is thus enabled to render his work efficient. It is sad to think how much scientific work is wasted because the labour is not wisely directed.

In German scientific writings the excellence of the matter usually contrasts vividly with the defective style and presentation. Indeed, the Germans, despite the superiority of their modern literature, are awkward writers, and too often slovenly in literary composition. Conciseness and clearness are good qualities, which may assuredly be attained by the expenditure of thought and pains ; but these the German investigator seems unwilling, in many cases, to bestow upon his pen-work, but follows the easier plan of great diffuseness. Besides this, another defect is not uncommon,--the ill-considered arrangement of the matter. This occurs in all degrees, from a wellnigh incredible confusion, to be sometimes found even in elaborate and important essays, to a slightly illogical order. In this regard, a curious and not infrequent variety of this fault deserves mention. According to the headings of the chapters or sections, the division of topics is perfect; but under each head the matters are tumbled together as if a clerk was contented to stuff his papers in anyhow, if only he crammed them into the right pigeon-hole.

Speaking broadly, the German mind lacks conspicuously the habits of clearness and order. There have been celebrated exceptions, but they were individual. The nation regards itself as having a decidedly philosophical bent, meaning a facility at taking broad and profound views of the known. We venture to contradict this opinion, doing it advisedly. Their profundity is mysticism, their breadth vagueness, yet a good philosopher must think clearly. It is a remarkable but little heeded fact, that Germany has not contributed her share to the generalisations of science; she has produced no Linné, Darwin, Lyell, Lavoisier, or Descartes, each of whom bequeathed to posterity a new realm of knowledge, although she has given to the world grand results. by the accumulated achievements of her investigators. The German's imperfect sense of humour is another obstacle which besets him on every path. He is cut off from the perception of some absurdity, like that of Kant's neumenon, for instance. One cannot explain this to him: it were easier to explain a shadow to the sun, who always sees the lighted side. To state the whole epigrammatically, German science is the professional investigation of detail, slowly attaining generalisations.

English science is the opposite of this,-amateurish rather than professional. Some might call it insular, yet we should hardly join them in so doing. In fact, the professional investigator has hardly been a recognised character in the English social organisation: until recently he was barely acknowleged, even by the universities, which sought instructors who knew and could teach, who might investigate and discover in a subsidiary, and, as it were, unofficial way. A large number of English scientific men were disconnected from the universities and colleges after their own student years, and were half or wholly amateurs; and their writings show the effects of this separation, not always, to be sure, but in many cases with painful evidence, by a lack of thoroughness, an imperfect acquaintance with other investigations, and a failure to grasp the essential part of the problem: in brief, such writings appear behindhand and superficial. Yet amid these poorer productions are to be found a right goodly number of the best scientific articles we possess in any language. Of late years the proportion of the good has steadily increased, and investigation is now more correctly appreciated than ever before. Indeed there is no more encouraging event in the recent progress of science than the sudden elevation of the standard of original research in England. The English are trained writers: their scientific articles excel the German in literary merit, being seldom slovenly either in arrangement or style, and rarely wearisome from sheer diffuseness. Very noteworthy is the fertility in generalisations of the English : this is with them the outcome of individual endowments, a single master attaining a broad conclusion-a process of individual effort quite unlike the German democratic method of generalising by the accumulations of many. Is it too much to say that the English and Scotch are the Greeks of modern philosophy?

French science is decidedly provincial: it is apart, having only an imperfect, uncertain acquaintance with the great world outside, and its international interests of original research. The French have lagged far behind the great movements of recent years. Consider only how backward they have been in the comprehension and acceptance of the Darwinian theory; and remember, too, that it were wiser to take out the mainspring from a watch than to eliminate evolution from biology. French scientific articles are well written, the matter is admirably classified, it is all very clear. The keen, artistic sense of the nation displays itself here; but it also deludes them into presenting a rounded survey of a greater field than is demanded by the actual discoveries they report. To satisfy this yearning for artistic completeness, elaborate and tedious disquisitions, and hackneyed principles, and facts long known, are interpolated; and even worse may be, when the imagination helps to create the completeness. Most scientific men harbour a little distrust of French work. This sentiment is further fostered by the almost systematic neglect of German research on the part of the French. Such a frank exhibition of rancour makes one suspect the impartiality of the French in science generally : indeed, we believe that science has never been so depressed in France as at present. Italy is above her; but Italy, with all her innate ability, is striving to learn from Germany, and has already risen high, and will rise higher. We trust and believe that the present phase of French science which abounds in inefficient work will soon end, and the people terminate their present voluntary isolation. The French stay at home : they used to travel abroad much. Let us hope that they will soon resume their ancient habit, and, above all, that they will reestablish mental intercourse with foreigners. There are savants in France who are esteemed throughout the scien. tific world: may their number rapidly increase!

America's contributions to pure science are by no means very extensive, or often very important: compared with the great volume of German production, they seem almost insignificant. We have never duly fostered research, for we have bestowed upon it neither the proper esteem nor office. There are, we suppose, at least six thousand 
"professors" in the United States: are one hundred and fifty of them active investigators? The time seems remote when every American professor will be expected to be also an investigator; but among us is a little band of men who have before them the model of Germany, and who are working earnestly for the intellectual elevation of their country. Taeir first object is necessarily to render $r z-$ search more important in public estimation, and so to smooth the way for a corps of professional investigators. Every thoughtful person must wish success to the attempt.

\section{THE GEODETIC CONGRESS}

THE most generally interesting part of the proceedings of the Geodetic Conference which has been sitting at Rome during the past week is that connected with the selection of a common first meridian.

The report of the Permanent Committee of the International Geodetic Association recommends to the Conference the general acceptance of the meridian of Greenwich; it was referred to a Special Committee composed of one representative for each of the following-England, the United States, Germany, Italy, France, and Hamburg. The report concludes thus :-

"We terminate our report by proposing to the Assembly the following resolutions:-

"The seventh General Conference of the International Geodetic Association, held at Rome, and in which representatives of Great Britain, together with the directors of the principal astronomical and nautical almanacs, and a delegate from the Coast and Geodetic Survey of the United States have taken part, after having discussed the questions of unification of longitudes by the adoption of an initia! meridian, and of the unification of time by the adoption of a universal hour, have come to the following conclusions :-

"Firstly, that the unification of longitudes and of hours is as equally desirable in the interests of science as in those of navigation, commerce, and international communication. The scientific and practical utility of this reform considerably outweighs the sacrifices and the trouble of arrangement to which it will put the minority of civilised nations. It should, therefore, be recom. mended to the Governments of all the States interested that it may be arranged and confirmed by an International Convention, so that henceforth one and the same system of longitudes may be employed in all the astronomical and nautical almanacs, in all the geodetic and topographical bureaux and institutes, and in all geographical and hydrographical charts.

"Secondly, that the Conference propose to the Governments to choose for the initial meridian that of Greenwich, inasmuch as that meridian fulfils, as a point of departure of longitudes, all the conditions required by science ; and that being already actually the most extensively used of all, it presents the greater probability of being generally accepted.

"Thirdly, That the longitudes should be reckoned from the meridian of Greenwich in the sole direction of from east to west, and from zero to $360^{\circ}$, or from zero to twenty-four hours; the meridians on the charts and th. longitudes in the registers should be indicated everywhere in hours and minutes of time, with liberty of adding the indication of the corresponding degrees.

"Fourthly, That the Conference recognises for certain scientific needs, and for the service of the great administrations of the means of communication, such as railways, steamship lines, telegraphs, and posts, the utility of adopting a universal hour, side by side with the local or national hours, which will necessarily continue to be employed in civil life.

"Fifthly, That the Conference recommends, as the point of departure of the universal hour and of cosmopolitan dates, the mean noon of Greenwich, which coincides with the instant of midnight or with the beginning of the civil day, situated at the twelfth hour, or at $180^{\circ}$, Greenwich. It follows that the universal time will correspond everywhere with the mean local time, reckoned from midnight, less twelve hours and the longitude of the place, and that the dates change at the antipodes of Greenwich.

"Sixthly, That it is desirable that those States which, in order to adhere to the unification of longitudes and of hours, will have to change their meridians, should adopt the new system of longitudes as quickly as possible in their observatories and official almanacs, in their geodetical, topographical, and hydrographical works, and in their new charts. As a means of transition it would be well that in new editions of old charts, on which it would be difficult to change the squares, the indications according to the new system should at least be inscribed alongside the enumeration of the old meridians.

"Seventhly, That these resolutions should be laid before the Governments and recommended to their friendly consideration with the expression of a hope that an International Convention confirming the unification of longitudes and of hours may be conclude 1 as quickly as possible by a special Conference."

The Report is signed by the president, General Ibanez, and the secretaries, Professors von Oppolzer and Hirsch, the latter being also the reporter.

The paragraph in Dr. Hirsch's report, in which, after considering the question of the choice of an initial meridian, he emphatically conveys the opinion of the Permanent Committee in favour of that of Greenwich, merits quotation :-

"It cannot be doubted that the problem should be solved in favour of the meridian of Greenwich. It is by far the most extensively used, and, from the geographical, nautical, astronomical, and cartographical points of view, best answers the two conditions required. In fact, the immense British Empire, with its $20,000,000$ of square kilometres and its $250,000,000$ of population, extends over all parts of the world. Its mercantile marine, numbering 40,000 ships, with a total of from $6,000,000$ to $9,000,000$ of tons, and an equipment of 370,000 men, surpasses in importance the ensemble of all other navies. It must also be added that a great many other countries, among which the most important in respect of their mercantile marine are the United States, Germany, Austria, and Italy, equally use the Greenwich meridian in navigation, whence it may be affirmed that 90 per cent. of the navigators throughout long voyages calculate their longitudes by the meridian of Greenwich."

The Report of the Special Committee on the above resolutions was read on the $22 n d$ before the general meeting of the Conference, and accepted, after a very animated debate.

Referring to the resolutions it is only requisite to state briefly that, according to the Times report, as sent back to the Conference by the Special Committee, they now stand as follows:-Numbers I, 2, 4, 6, and 7 were adopted by the Committee without alteration; the other two were modified, or rather abbreviated, and now read thus :-

"Thirdly, that the longitude should be reckoned from the meridian of Greenwich, in the sole direction of from west to east.

"Fiftbly, That the Conference recommends, as the point of departure of the universal hour, and of cosmopolitan date, the mean noon of Greenwich, which coincides with the instant of midnight, or with the beginning of the civil day, under the meridian situated at 12 hours, or $180^{\circ}$, from Greenwich; the universal hours to be counted from zero to 24 ."

To these seven resolutions the Special Committee have 